\title{
Chapter 6 \\ The Faceless Mobile Youth of Africa Drive Change
}

\author{
Darelle van Greunen and Alida Veldsman
}

\subsection{Background}

One of the major challenges facing most developing countries such as South Africa today is how to take full and smart advantage of quite spectacular and far-reaching advances in science and technology not only in promoting national economic development but particularly addressing the needs of poor and marginalised sections of society. Whilst technology access in the pre-digital era has always been a major barrier to economic and social development in developing countries, this is no longer an absolute barrier for at least three reasons: first, the proliferation of distributive and open technologies, and limits to the power of proprietary frameworks; second, the increasingly lower delivery cost of new technologies; and third, the emergence of multiple sources of technology innovation and development in civil society.

Despite this, it is not altogether clear that South Africa is sufficiently exploiting the multiplier effects of new technology opportunities across the traditional rural and urban, and black and white social barriers, especially insofar as real empowerment of the poor and marginalised are concerned. There is still, in some respects a growing, technological divide in our country, and the dividends of our technological age are rarely passed on equally to different social classes, ethnic groups and geographic communities in South Africa. The problem of a continued technological gap may be partly to do with the economics of 'access' by poor communities. However, there also seems to be major problems with the absence or weakness of requisite conditions - social, institutional and political-necessary for its effective social appropriation.

D. van Greunen $(\varangle) \cdot$ A. Veldsman

The Centre for Community Technologies, Nelson Mandela University,

Port Elizabeth, South Africa

e-mail: Darelle.vanGreunen@mandela.ac.za

A. Veldsman

e-mail: Alida.Veldsman@mandela.ac.za

(C) The Author(s) 2018

61

S. Hostettler et al. (eds.), Technologies for Development,

https://doi.org/10.1007/978-3-319-91068-0_6 
Technology has significantly changed the way in which young people interact with one another and the world around them. The youth use the Internet or a mobile phone to source information, engage, construct and maintain social networks. Technologies have dramatically transformed young people's relationships with one another, their families and communities. In South Africa, 75\% of youth even in rural areas has access to a mobile phone (Eyebers and Giannakopoulos 2015). This not only yields opportunities for access to different types of information but also to create a faceless connected force of youth.

This paper sets out to explore the potential of using mobile phone technology to drive change amongst at-risk youth in a low-income community that is severely challenged by social issues.

\subsection{Why the Northern Areas?}

The Nelson Mandela Bay Metro is located on the southern coast of South Africa. The total population amounts to some 1.5 million of which some $\pm 182,000$ people live in the Northern Suburbs (Bloemendal, Bethelsdorp and Gelvandale) of Port Elizabeth (StatsSA 2011). Although the situation changes constantly as a result of socio-economic and other circumstances, it is estimated that there are approximately 40,000 households in informal areas with an additional 50,000 qualifying households in backyard shacks. Distorted development in Nelson Mandela Bay has manifested in a highly skewed distribution of income and wealth. The unemployment rate is over $35 \%$ of the total population (StatsSA 2011). At least $44 \%$ of households access at least one social grant with $20 \%$ of residents not having any or limited schooling.

Daily, the Northern Areas communities face some form of crisis, disaster or situation. The community members are currently downcast and stuck in a perpetual cycle of poverty, sickness, crime and hopelessness, and therefore do not progress but regress and are in need of bold moves to be taken towards poverty eradication, medical relief, unemployment eradication, crime eradication and development of the future leaders of not only this area but also the country as a whole. Gang culture has influenced life in the Northern Areas since the early 70s, with the birth of notorious gangs, such as the Mongrels, Mafias, 40 Thieves and Fire Boys. These gangs warred over turf and were greatly influenced by the code of the prison gangs. As more young men went through the prison system, and as gang groups split and splintered, more street gangs developed and gang culture became more ingrained.

The majority of young people who become involved with gangs are enticed by the hopes of financial gain, peer pressure or out of rebellion against parents and other forms of authority. Scores of young people, including pupils from the Northern Area schools, were murdered in violent gang-related attacks in recent years. Local press reports on gang violence and murders on a daily basis. According to the SAPS statistics between mid-2014 and January 2015, 59 gang-related murders were committed in the Northern Areas of Port Elizabeth; and 120 cases of attempted murder are being 
investigated. The police also claim that children as young as twelve are being lured into gangs and are groomed for the gang lifestyle.

Matavire (2007) describes Helenvale, a suburb in the Northern Areas of Port Elizabeth as a 'filthy, overcrowded and crime-ridden suburb... The Northern Areas township, which is predominantly coloured, and one of the oldest in Port Elizabeth, is characterized by extreme poverty and lack of service delivery. It has a population of more than 14,000, of which 75\% have no income. The average income per household is estimated at R400 a month. At least $7 \%$ of the residents have no formal education. Overcrowding is a concern and, although most houses have toilets, they are shared between 10 and 20 people...The suburb had been planned during apartheid and the infrastructure is now falling apart-sewerage, housing and other facilities...'.

\subsection{Problem Description}

The poverty experienced by these communities has left the members with low selfesteem. This is because they are unable to meet their basic needs. This population also lacks life skills that would enable them to meet their needs and perform their duties to the optimal capacity. This deprivation has led them to believe that they do not measure up to others who meet their family needs and lead quality lives. Educational underachievement occurs in every school in South Africa. It is caused by various factors and although it has negative consequences for the individual, the school, the community and the country as a whole, teachers and parents tend to simplify the problem by ascribing it to the 'laziness and stupidity' of the learners. This problem is emphasised in the Northern Areas of Port Elizabeth. An area challenged by severe social problems including poor health, substance abuse, domestic violence, gang fighting and teenage pregnancies. There is currently a big discrepancy in the number of children from the Northern Areas, starting school and those finishing grade twelve. The learners from the Northern Areas are academically underachieving. This is a problem because academic underachievement contributes to a vicious cycle of failure, behavioural problems, school dropout, unemployment, overcrowding, social problems and a general feeling of worthlessness. Children from an early age on a daily basis use drugs.

There is a need to understand what will empower the youth to drive change. In a society where people fear for their lives on a daily basis, there is a need to investigate other means of driving change. Currently, the social disconnect in the Northern Areas necessitates alternate forms of communication and support towards change. 


\subsection{Research Objectives}

The objective of the research is to determine how Information Communication Technology (ICT) can be used to act as the driver of change without excluding human participation. What social structural factors relate to unique patterns in youth mobile phone usage in low-income areas faced with severe social challenges? We suggest that certain social dynamics inherent in the institutions of family, public places and peer relations are key factors. The youth use mobile phones because they enable new kinds of social contact, but also because different socio-economic environments are limited in access to adult forms of social organisation. This paper relies on ethnographic observations of members of a youth leadership academy as well as surveys and interviews conducted with different youths representing the Northern Areas community.

\subsection{Methodology}

Drawing on articles and reports by academics combined with ethnographic observations, this paper encompasses a range of disciplines including education, sociology, culture and information technology. Whilst the paper draws upon a variety of literature, the focus is on the South African context. An exploratory case study approach is adopted that applies interviews, surveys and direct observations as data collection mechanisms.

\subsection{Mobile Youth Culture}

Adolescents and young people have been identified as the first adopters of mobile technology with 72\% of 15-24 year olds reported as having a cell phone in a national survey conducted by the Kaiser Family Foundation (2007) and the South African Broadcast Corporation in South Africa in 2007. Prepaid mobile subscriptions are cheap, do not require the user to have a bank account, physical or postal address and airtime can be bought as money becomes available. Together with services such as 'Please Call Me', which is a free notification service that a user can send to another person's phone, and 'WhatsApp', which allows users to exchange messages without having to pay for SMS, made mobile phones the preferred communication tool among the youth. Since phones are usually handed-down to the junior members in a household, as the parents upgrade to newer and better devices, the problem of obtaining phones does not exist.

Where adults tend to have more conservative uses for mobile phones, young people find mobile phones quite liberating as it allows them access to just about anything they are interested in, anywhere, any time. To the youth today, mobile phones have 
become an extension of themselves. It is therefore not surprising that the youth uses their phones to interact socially via apps like Facebook Messenger, Pinterest, Instagram and WhatsApp to name but a few. Through Facebook, Twitter, MySpace and other social media networks, youths create virtual communities that not only give them a voice but also offer anonymity. Virtual communities are slowly replacing faceto-face communication. It would therefore be shortsighted not to utilise these new ways of communicating and interacting as a mechanism to drive change and build resilience among at-risk-youth.

The role of digital literacy and cyber safety is established, although policy and practice have been slow to respond to new ways of thinking about media literacy in a digital world. Traditionally, media literacy has been understood and taught in relation to mass media, addressing issues of media ownership, censorship and advertising. However, today's online and networked media environment requires a more complex digital literacy that is often not explicitly taught in school. This environment requires that young people develop new skills to participate and stay safe in the new digital media environment. Consequently, there are a number of components to technology literacy (Third and Richardson 2010). These include the following:

- Technical literacy - for example, the knowledge and skills required to use a computer, web browser or particular software programme or application;

- Critical content literacy - the ability to effectively use search engines and understand who or what organisations created or sponsor the information; where the information comes from and its credibility and/or nature;

- Communicative and social networking literacy - an understanding of the many different spaces of communication on the web; what is appropriate digital behaviour; level of privacy (and therefore level of safe self -disclosure for each); and how to deal with unwanted or inappropriate communication through them;

- Creative content and visual literacy - in addition to the skills to create and upload image and video content, this includes understanding how online visual content is edited and constructed, what kind of content is appropriate;

- Mobile media literacy-familiarity with the skills and forms of communication specific to mobile phones (e.g. text messaging/instant messaging); mobile web literacy, and an understanding of mobile phone etiquettes.

\subsection{Social Media}

Although people have been using the Internet to connect with others since the early 1980 s, it is only in the last decade that social networking services have proliferated and their use has become a widespread practice-particularly amongst young people (Johnson et al. 2009). Social media is generally used to describe collaborative media creation and sharing on a fairly large scale but is extended to include microcommunities. The uptake of social media in its various forms signifies a shift in how technology use has changed from primarily an information and entertainment source 
to one of communication. Young people are consuming, producing, sharing and remixing media (Burns et al. 2008). This participatory media environment enables young people to engage in creative content production, empowering them with new means of creating and sustaining connections with others. It has also opened up new debates on how to conceptualise and promote what has come to be termed cyber citizenship or digital citizenship (Coleman and Rowe 2005).

In South Africa, thousands of students have taken to social media to drive change as the recent 'fees must fall' student protest actions in South Africa demonstrated. Social media platforms such as Facebook and Twitter buzzed with live updates of the protest, and as it gained momentum in South Africa, so did it gain even international support with messages of solidarity streaming in from institution across the globe. Social media is the voice of the youth today.

\subsection{Case Study: Northern Areas Youth Leadership Academy (YLA)}

This initiative was established in 2011 with the first series of activities commencing in 2012. The Northern Areas Youth Leadership Academy's goal is to educate the youth, strengthen the family and rebuild the community by aiding and supporting the educational, spiritual, moral and social development of at-risk-youth. The initiative also aims to use ICT and its various forms as an instrument to create micro-communities or clusters of young people who take ownership of the society that they will grow to inherit. It then envisioned that ICT and then more specifically mobile technology could support an increased civic engagement.

The use of mobile technology as a means of sharing information, encouraging and education at-risk youth has resulted in the establishment of an engaged and connected community. Not only are there now a new generation of leaders but also a new generation of leaders who have a sense of purpose and the will to bring about change in their society. The case study did not follow the traditional six steps of a case study as described by Yin (2014). Instead, the underlying principles of change management were employed to create the micro-community that uses technology to drive change.

\subsection{Phases of Drive Change}

\section{Preparation phase}

This intervention differs from other socio-economic initiatives in the Northern Areas as it is giving voice to the young people living in the community. It aims to channel youth energy in a positive way to restore the social structures in their communities. In order to do this, the initiative builds on existing capacities by strengthening natural 
leaders and building leadership capacity in those who exhibit leadership characteristics. School principals are requested to identify potential candidates in Grade 11. Selection of participants is based on a screening document but it is up to the individual to decide whether or not to enrol in the academy.

\section{Manage expectations and outcomes phase}

Enrolled youth are expected to commit two hours of their time every Saturday afternoon, from March till November. During this time, they participate in interactive workshops, seminars and other activities aimed at building leadership skills but which is also fun. University lecturers, community leaders and other subject experts offer their time and expertise to engage with the participants during these sessions. Recognition is given to those participants who exhibited dedication by attending a minimum of $70 \%$ of the sessions, during a formal event. This event marked the end of the programme and is attended by all involved as well the parents and guardians of the participants. Each participant is expected to share his/her experience of the programme with the audience. This in itself is a significant indicator of the level of growth of each individual.

\section{Develop emotional quotient (EQ) phase}

Emotional intelligence plays a significant role in the development of young people as it allows them to recognise their own and other people's emotions, to discriminate between the different feelings and to act upon it in an appropriate manner. EQ subject experts facilitate workshops to build EQ skills and social competence, especially for young people whose mode of communication is now via social networks and virtual communities.

\section{Create street law awareness phase}

In order to take full advantage of the changing face of communication in terms of atrisk youth, one has to understand the challenges they are faced with on a daily basis. It is therefore not only necessary to sensitise the youth about bad or potentially bad situations, whether it is emotional or physical abuse, sociological and psychological pitfalls or improper practices at institutional level. But recognition of potentially dangerous situations alone does not empower a person to act appropriately. There is thus a need to empower the youth to know their rights and to take action.

Street law taught by law students from the Faculty of Law at the NMMU has therefore become an integral part of the YLA programme. Participants simulate potentially bad situations and are guided by the facilitators on how to act upon each situation. This led to the establishment of Street Law WhatsApp groups where group members can get support or even summon help when in a bad situation. For the girls, this proved to be exceptionally valuable.

\section{Create awareness of responsible digital citizenship phase}

The perceived distance and anonymity created by electronic communication methods have resulted in unacceptable and undesirable communication behaviours among the 
youth. A study conducted in Nelson Mandela Bay in Port Elizabeth among 1594 primary and secondary school children, indicated that $36 \%$ of the respondents had experienced some form of cyberbullying (Badenhorst 2011). South Africa is lacking specific legislation dealing with cyberbullying leaving victims to rely on remedies offered by criminal law or civil law. Youth leaders have a significant role to play in creating awareness about the types of behaviour that constitute cyberbullying as well as how and where cyberbullying can be reported. Being part of virtual communities themselves, allow them to build positive digital citizenship among members and share the various helplines and support groups with their peers.

\subsection{Using ICT to Drive Change}

\section{Understanding change}

In order to effect change, one has to know what the condition is that needs to be changed, what the preferred future condition should be and how to go about it. New youth leaders are therefore put through a structured change management process to drive change, where after they have to apply it to their personal lives. This exercise provides valuable insight into the kind of undesirable situations young people are faced within their communities. Issues such as drug and alcohol abuse, gangsterism, teenage pregnancies, violence, disrespect and disorderly behaviour impact negatively on their lives. Early school dropouts are leaving the available workforce unskilled, thus adding to the already high level of unemployment.

\section{The role of ICT}

Today's youth are much more comfortable with using technology than previous generations. They are therefore encouraged to develop the capacity to solve challenges and so drive change in their own communities using mobile technology. The Northern Areas computer facilities were established with specifically this in mind. Not only are desktop computers available for computer literacy training but also tablets to make technology attractive for the younger generation. At-risk youth are encouraged to make use of the facility to first educate them about ICT facilitates the creation and sharing of information. The focus is on protecting their will to use ICT to drive change in a manner that will encourage change but keeping the potential threats in mind. Threats include the risk of cybercrime and bullying, inappropriate use of the technology to support criminal activities or even the use of technology for the production of inappropriate materials such as pornography.

Since 2012 to date, the use of various forms of technologies is observed. The technologies range from structured uses in a controlled environment such as the computer facilities in a protected area to own mobile phones in a virtual world with potentially an unknown identity. Over time, the following lessons and changes were observed: 
- Individual identity and self-expression amongst the youth of the Northern Areas is developing at an increasing rate. The flexibility of mobile technology to encourage individual customization also enhances the ability to express identity. Mobile technology is found to through the use of social media reinforce parts of youth identity including societal and cultural background.

- Strengthening of interpersonal relationships through the use of instant messaging, WhatsApp and social networking. These technologies address the specific barriers in the Northern Areas that young people may face to forming and maintaining positive social relationships. Mobile technology has removed these barriers because they are accessible 24/7, from different physical locations and via different technologies such as mobile phones and tablet PCs. The use of different forms of online social networking, such as instant messaging, is now established to support networks with peers. In addition, youths who are marginalised and socially isolated are now using the opportunity to socialise using technology.

- Convergence of online and offline spaces is now on the increase. It is evident in the observations that young people are increasingly engaging simultaneously in online and offline social networking. It appears that young people often work collaboratively in the online space through WhatsApp, for example, creating or commenting on YouTube videos or other such activities, while physically colocated. They not only consider their online and offline worlds as one but also use this to create a sense of belonging and connectedness with peers.

- Civic engagement via technology has evolved into an opportunity for the Northern Areas youth to share information and to create issue-oriented groups. Social networking services are used to find out what other people are doing by connecting with individuals with similar interests, existing activities or disseminating information about their own projects. At-risk youth are now creating new participatory communities by and for their peers to allow participation in a virtual environment rather than facing the day-to-day challenges of the Northern Areas.

\subsection{Humanising Pedagogy}

For decades, educators and others considered various strategies to close the gap for at-risk youth. They have sought solutions involving new uses of technology. In some instances, the results of technology initiatives have been mixed. Often the introduction of technology has failed to meet the expectations leaving specifically the educational landscape replete with stories of how at-risk youth were unable to benefit from particular innovations. In this particular initiative, an approach of humanising pedagogy was taken. Rather than using technology to drill and kill the enthusiasm of the youth, technology was used as an interactive instrument. Through the use of interactive engagement using technology, the notion of vulnerability is explored and employed as a developmental and human security context that explores the interdependence between human beings and technology. Ultimately, the aim is to develop an embedded pedagogy that can enhance educational engagement in a non-threatening manner using technology. 


\subsection{Conclusion and Future Work}

The use of mobile technologies and then specifically the instant messaging and social media are transforming communication practices, opening new spaces and processes of socialisation and impacting upon traditional social structures. These effects are particularly relevant for the most frequent users of the technologies namely youth. This new environment poses certain challenges and, like any setting for social interaction, has some inherent risks. However, this paper suggests that through increased Internet and media literacy - ensuring all young people develop the skills to critically understand, analyse and create media content-these challenges can be overcome and risks mitigated in a way that ensures the many benefits of ICT and more specifically mobile technologies can be realised.

In other words, by maximising the benefits of mobile technology, whether it is its role in delivering educational outcomes, or facilitating supportive relationships, identity formation, or a sense of belonging and resiliency, many of the risks of virtual interaction, such as cyberbullying, can be minimised. Strategies to this end must be underpinned by best practice change management evidence and more research should be undertaken to ensure that emerging practices and effects of mobile technology as a driver of change are understood and responded to.

This paper finds that the benefits of mobile technologies are largely associated with the participatory nature of the modern digital environment. There remains a need for exploratory academic work on cybercitizenship amongst at-risk youth and the ways in which such youths are engaging online to express their views, challenge and create their own modern views on society. This knowledge could lead to the recognition that their online practices may challenge commonly held notions about childhood, youth, gender and other critical social issues.

It is important to note that new digital communication practices could well be informed by the experiences and perspectives of the new generation of mobile youth with their view of digital literacy. This in turn could lead to a better understanding of how the online and offline worlds are integrated to drive change whilst using ICT as the tool for change.

Ongoing evaluation of the intervention feeds into the offerings and influence the respective technologies and content that is contained in the intervention. The next step is to now replicate the intervention in similar communities based on the lessons learnt and the good practices that have evolved from this exploratory study. Some examples for replication include the use of similar technologies for at-risk groups including refugees, abused women and as a means to support addiction treatment. Some considerations for the replication of the study would include connectivity, appropriate support applications that allow for the different types of support required, and appropriate interaction techniques to allow for varying digital literacy levels. 


\section{References}

Badenhorst, C. (2011). Legal responses to cyber bullying and texting in South Africa: Centre for Justice and Crime Prevention CJCP Issue Paper No 10.

Burns, J. M., Durkin, L. A., \& Nicholas, J. (2008). ReachOut! The Internet as a setting for mental health promotion and prevention in Éisteach: Journal of the Irish Association of Counseling and Psychotherapy, 8(1), 13-19.

Coleman, S., \& Rowe, C. (2005). Remixing citizenship: Democracy and young people's use of the internet a report for the Carnegie Young People's Initiative.

Eyebers, S and Giannakopoulos, A. (2015) The Utilisation of Mobile Tecnologies in Higher Education: Lifebuyo or Constriction? In mLearn 2015 CCIS 560, pp. 300 - 315. T.H. Brown and H.J. van der Merwe (Eds) in Springer Switzerland.

Johnson, L., Levine, A., \& Smith, R. (2009). The 2009 horizon report. Austin, Texas: The New Media Consortium.

Kaiser Family Foundation. (2007). Young South Africans, broadcast media, and HIV/AIDS awareness: Results of a national survey, 2007, URL http://www.kff.org/southafrica/upload/7614pdf. Accessed January 22, 2016).

Matavire, M. (2007, May 19). Bhisho has reneged on promise, says ANC. The Herald, 9.

Statistics South Africa (StatsSA). (2015). Sensus 2011. http://www.statssa.gov.za/publications/ P03014/P030142011.pdf. Accessed January 22, 2016).

Third and Richardson. (2010). Connecting, supporting and empowering young people living with chronic illness and disability: The livewire online community, (Report prepared for the Starlight Children's Foundation, January 2010). SBN: 978-0-86905-997-5.

Yin, R. K. (2014). Case study research. Design and methods (5th ed.). Thousand Oaks: Sage Publications.

Open Access This chapter is licensed under the terms of the Creative Commons Attribution 4.0 International License (http://creativecommons.org/licenses/by/4.0/), which permits use, sharing, adaptation, distribution and reproduction in any medium or format, as long as you give appropriate credit to the original author(s) and the source, provide a link to the Creative Commons license and indicate if changes were made.

The images or other third party material in this chapter are included in the chapter's Creative Commons license, unless indicated otherwise in a credit line to the material. If material is not included in the chapter's Creative Commons license and your intended use is not permitted by statutory regulation or exceeds the permitted use, you will need to obtain permission directly from the copyright holder.

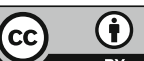

